Check for updates

Cite this: Chem. Commun., 2019, 55, 11358

Received 25th July 2019,

Accepted 19th August 2019

DOI: $10.1039 / c 9 c c 05759 e$

rsc.li/chemcomm

\section{Ratiometric two-photon fluorescent probe for in situ imaging of carboxylesterase (CE)-mediated mitochondrial acidification during medication $\dagger$}

\author{
Ao Jiang, ${ }^{a}$ Guang Chen, (D) *a Jie Xu, ${ }^{a}$ Yuxia Liu, (D) ${ }^{a}$ Guanghui Zhao, ${ }^{a}$ Zhenjun Liu, ${ }^{a}$ \\ Tao Chen, ${ }^{\mathrm{ab}}$ Yulin Li ${ }^{\mathrm{ab}}$ and Tony D. James (D) *ac
}

\begin{abstract}
We report on a dual ratiometric two-photon fluorescent probe for in situ sensing of mitochondrial $\mathrm{CE}$ activity and $\mathrm{pH}$. Using the probe it is possible to visualize the CE-mediated acidification of hepatoma cells and hepatic tissues during medication with antipyretic antiinflammatory drugs.
\end{abstract}

Carboxylesterase (CE) is an important enzyme for ester drugs including antipyretic and anti-inflammatory medicines. ${ }^{1} \mathrm{CE}$ mainly exists in the endoplasmic reticulum as well as mitochondria. These two organelles are in close contact, resulting in high levels of CE near the mitochondria. ${ }^{2}$ During the metabolism of these drugs, CE participates in the hydrolysis of esters and the resultant acidic metabolites may cause the acidification of mitochondria. Mitochondria are one of the most vital organelles in cells, ${ }^{3}$ and their acidification is extremely dangerous especially for mitochondrial division. ${ }^{4}$ Therefore, exploring CE-mediated mitochondrial acidification is essential for understanding the enzyme triggered organelle aberrations.

During drug administration, the acidification of mitochondria can be caused by CE-generated metabolites. Therefore, a molecular probe is required that can successively respond to $\mathrm{CE}$ activity and $\mathrm{pH}$, in order to visually explore CE-mediated $\mathrm{pH}$ variation during the administration of ester drugs. For many years, researchers have developed various molecular probes, ${ }^{5}$ many of which can be used for report CE activity ${ }^{6}$ or $\mathrm{pH} .{ }^{7}$ Unfortunately, there is no molecular probe for the consecutive reporting of CE activity and $\mathrm{pH}$. Therefore, with this research, we present the

\footnotetext{
${ }^{a}$ The Key Laboratory of Life-Organic Analysis, Key Laboratory of Pharmaceutical Intermediates and Analysis of Natural Medicine, College of Chemistry and Chemical Engineering, Qufu Normal University, The school attached to Qufu Normal University, Qufu 273165, China. E-mail: chenandguang@163.com

${ }^{b}$ Key Laboratory of Tibetan Medicine Research \& Qinghai Key Laboratory of Qinghai-Tibet Plateau Biological Resources, Northwest Institute of Plateau Biology, Chinese Academy of Science, Xining 810001, Qinghai, P. R. China ${ }^{c}$ Department of Chemistry, University of Bath, Bath, BA2 7AY, UK. E-mail: t.d.james@bath.ac.uk

$\dagger$ Electronic supplementary information (ESI) available. See DOI: 10.1039/c9cc05759e
}

design of a ratiometric two-photon fluorescent probe for the in situ imaging the $\mathrm{CE}$ activity and $\mathrm{pH}$ in mitochondria.

Mitochondria-targeting groups are usually positive groups, that can exit the mitochondria during cellular acidification, therefore causing a loss of in situ information about the mitochondria. Therefore, with our design, we synthesized the 1-(4-(chloromethyl)benzyl)-4-methylpyridin-1-ium with 4-methylpyridine and 1,4-bis(chloromethyl)benzene (Fig. S1, ESI $\dagger$ ). This molecule has both a positive charge for mitochondria targeting and a benzyl chloride group that can covalently lock the probe with the mitochondria, allowing for the in situ evaluation of mitochondrial information even under the acidic conditions. With this precursor, we next obtained the $(E)$-1-(4-(chloromethyl)benzyl)-4-(2-(7-hydroxy-2-oxo-2H-chromen-3-yl)pyridin-1ium (HMT)). HMT responds to changes of $\mathrm{pH}$ in a reversible ratiometric manner. Finally, we transformed the hydroxyl of HMT into carboxylic esters to produce the CEMT probe. According to our design, CEMT can target and lock with the mitochondria, and be triggered by mitochondrial CE to produce HMT which can then reversibly monitor the variation of $\mathrm{pH}$ in the mitochondria (Scheme 1).

With the probe CEMT in hand, we investigated its properties. Fig. 1 shows that, with the increase of CE, the emission of CEMT at $460 \mathrm{~nm}(\mathrm{Ex}=410 \mathrm{~nm})$ decreases gradually while the emission

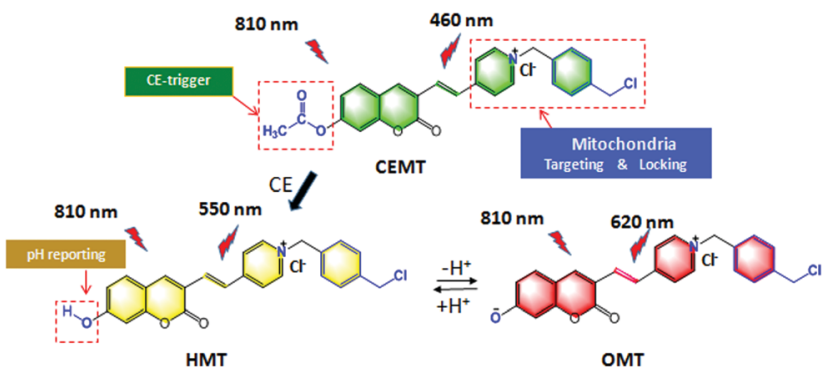

Scheme 1 Design and sensing mechanism of a ratiometric two-photon mitochondria-locked probe CEMT toward carboxylesterase (CE) activity and $\mathrm{pH}$. 

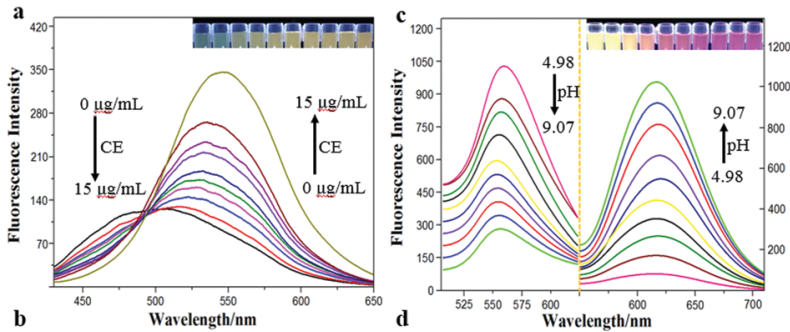

b
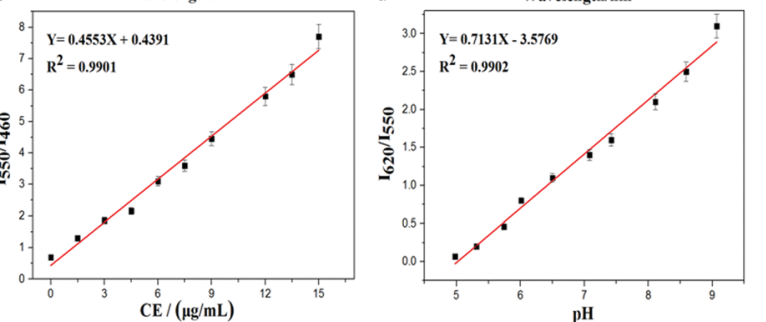

Fig. 1 Optical response to $\mathrm{CE}$ activity and pH. (a) Fluorescence spectra changes and (b) fluorescent intensity ratio $\left(/_{550} / /_{460}\right)$ of CEMT $(10 \mu \mathrm{M})$ in the presence of carboxylesterase $\left(0 \mu \mathrm{g} \mathrm{mL}^{-1}, 1.5 \mu \mathrm{g} \mathrm{mL}^{-1}, 3.0 \mu \mathrm{g} \mathrm{mL}\right.$, $4.5 \mu \mathrm{g} \mathrm{mL}-1,6.0 \mu \mathrm{g} \mathrm{mL}^{-1}, 7.5 \mu \mathrm{g} \mathrm{mL}^{-1}, 9.0 \mu \mathrm{g} \mathrm{mL}^{-1}, 12.0 \mu \mathrm{g} \mathrm{mL}^{-1}$, $13.5 \mu \mathrm{g} \mathrm{mL}^{-1}, 15.0 \mu \mathrm{g} \mathrm{mL}^{-1}$ ) in $\mathrm{B}-\mathrm{R}$ buffer solution $(\mathrm{pH}=7.42,40 \mathrm{mM})$ at $37^{\circ} \mathrm{C}$. $\lambda_{\mathrm{ex}}=410 \mathrm{~nm}$. (c) Fluorescence spectra changes and (d) fluorescent intensity ratio $\left(/_{620} / /_{550}\right)$ of $\mathrm{HMT}(10 \mu \mathrm{M})$ in the presence of in $40 \mathrm{mM} \mathrm{B}-\mathrm{R}$ buffer solution at various $\mathrm{pH}(4.98,5.31,5.74,6.01,6.50,7.08,7.42,8.31$, $8.59,9.07)\left(\lambda_{\mathrm{ex}}=410 \mathrm{~nm}\right.$ and $\left.530 \mathrm{~nm}\right)$.

at $550 \mathrm{~nm}(\mathrm{Ex}=410 \mathrm{~nm})$ increases linearly $\left(I_{550} / I_{460}\right)$. The ratiometric response of ultraviolet absorption is observed (Fig. S4, $\mathrm{ESI} \dagger$ ), which is consistent with the fluorescence properties. Next, we investigated the fluorescence response of HMT to $\mathrm{pH}$.

As Fig. 1 indicates, with increasing pH (5.0-9.0), the fluorescence intensity of HMT at $550 \mathrm{~nm}$ decreases, while the fluorescence intensity at $620 \mathrm{~nm}(\mathrm{Ex}=530 \mathrm{~nm})$ increases, with good linear correlation towards $\mathrm{pH}$ for the $I_{620} / I_{550}$ ratio. The reversibility for reporting $\mathrm{pH}$ was satisfactory (Fig. S7, ESI $\dagger$ ). We then evaluated the ability of CEMT to report CE activity and $\mathrm{pH}$. As shown in Fig. 2, CEMT displayed a ratiometric response $\left(I_{550} / I_{460}\right)$ towards increasing amounts of CE $\left(0-15 \mu \mathrm{g} \mathrm{mL}{ }^{-1}\right)$. Subsequently, B-R buffer was added to generate $\mathrm{pH}$ values from 5.0 to 9.0 , resulting in a ratiometric response $\left(I_{620} / I_{550}\right)$. Thus, CEMT was suitable for the consecutive reporting of CE activity and pH. Finally, we validated the ability of CEMT to target and lock at the mitochondria. As shown in Fig. 3, the co-localization
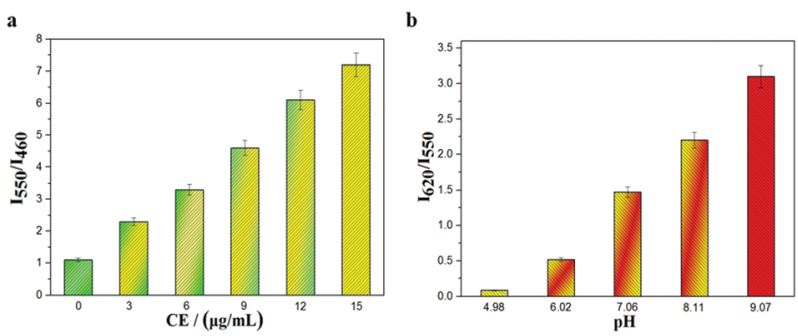

Fig. 2 (a) Fluorescence ratio of probe CEMT $(10.0 \mu \mathrm{M})$ in $\mathrm{B}-\mathrm{R}$ buffer solution $(\mathrm{pH}=7.42,40 \mathrm{mM})$ toward $\mathrm{CE}\left(0,3.1,6.0,9.2,11.9\right.$ and $\left.15.0 \mu \mathrm{g} \mathrm{mL}^{-1}\right)$. (b) $\mathrm{B}-\mathrm{R}$ buffer was added to the resulting mixture of (a) to give a $\mathrm{pH}$ values of $4.98-9.07\left(\lambda_{\mathrm{ex}}=410 \mathrm{~nm}\right.$ and $\left.530 \mathrm{~nm}\right)$. a
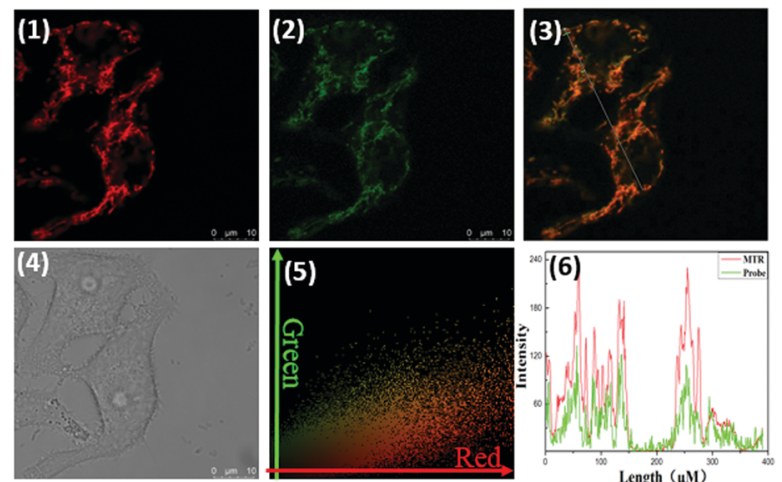

b
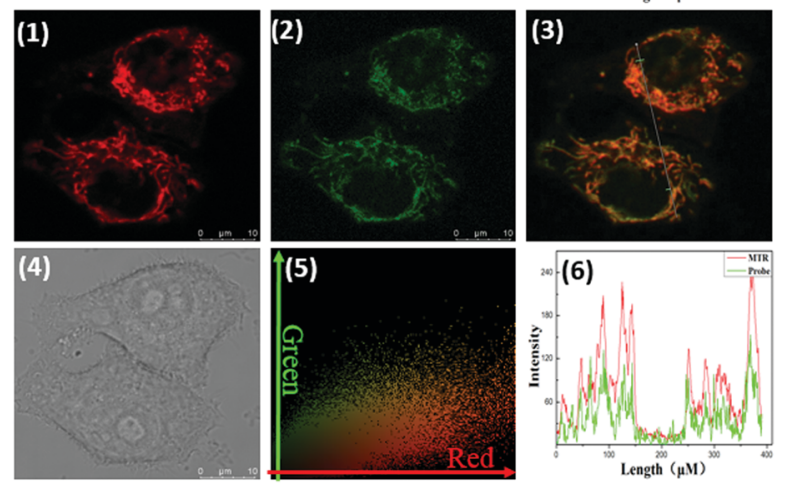

Fig. 3 Colocalization experiments of probe HMT and Mito Tracker Deep Red (MTDR) in HepG2 cells. The cells were incubated with HMT $(10 \mu M)$ for 20 min at $37^{\circ} \mathrm{C}((\mathrm{a}): \mathrm{pH}=7.40$; (b): $\mathrm{pH}=4.98)$, and the medium was replaced with fresh medium containing MTDR $(0.1 \mu \mathrm{M})$ and incubated for 15 min. Images for MTDR (1) and HMT (2) were then recorded using excitation wavelengths of 633 and $488 \mathrm{~nm}$, and collection windows were at 660-740 nm and 500-570 nm, respectively. (3) The merged images of (1) and (2). (4) The bright field. (5) The correlation between red and green channels in (3). (6) Pixel correlation across arrow in (3). Scale bar: $10 \mu \mathrm{m}$.

experiments of HMT with MTDR (mitochondrial targeting deep red dye: $\mathrm{Ex}=640 \mathrm{~nm}$; Em $=662 \mathrm{~nm}$ ) indicates that the Pearson's co-localization coefficient was 0.91 , demonstrating good targeting ability of CEMT. Subsequently, we changed the pH to 5.0 with B-R buffer and obtained the co-localization coefficients of HMT with MTDR as 0.89 . These results demonstrate that although the mitochondria were acidified, probe leakage from the mitochondria was negligible. Therefore, CEMT can be used for the in situ imaging of mitochondrial CE activity and $\mathrm{pH}$.

Therefore, we investigated the ability of CEMT to image CEmediated acidification in cells. As shown in Fig. 4-1, the control group exhibited fluorescence in the yellow channel and the red channel. The two ratios, R1 $\left(I_{550} / I_{460}\right)$ and R2 $\left(I_{620} / I_{550}\right)$, indicate the CE activity and pH (Fig. 4-1). Then, enzyme inhibitor BNPP (bis-para-nitrophenylphosphate) was added to group 2 before incubation with CEMT. As shown in Fig. 4-2, compared to the control group, fluorescence of the green channel was significantly enhanced, while the fluorescence of both yellow channel and red channel was very weak. This result indicated that BNPP effectively inhibited CE activity, which confirmed that the yellow fluorescence in the control group was due to CE activity. In group 3, we added vinyl acetate, a well-known CE-mediated acidizing agent, ${ }^{8}$ to investigate the response pattern of CEMT to 


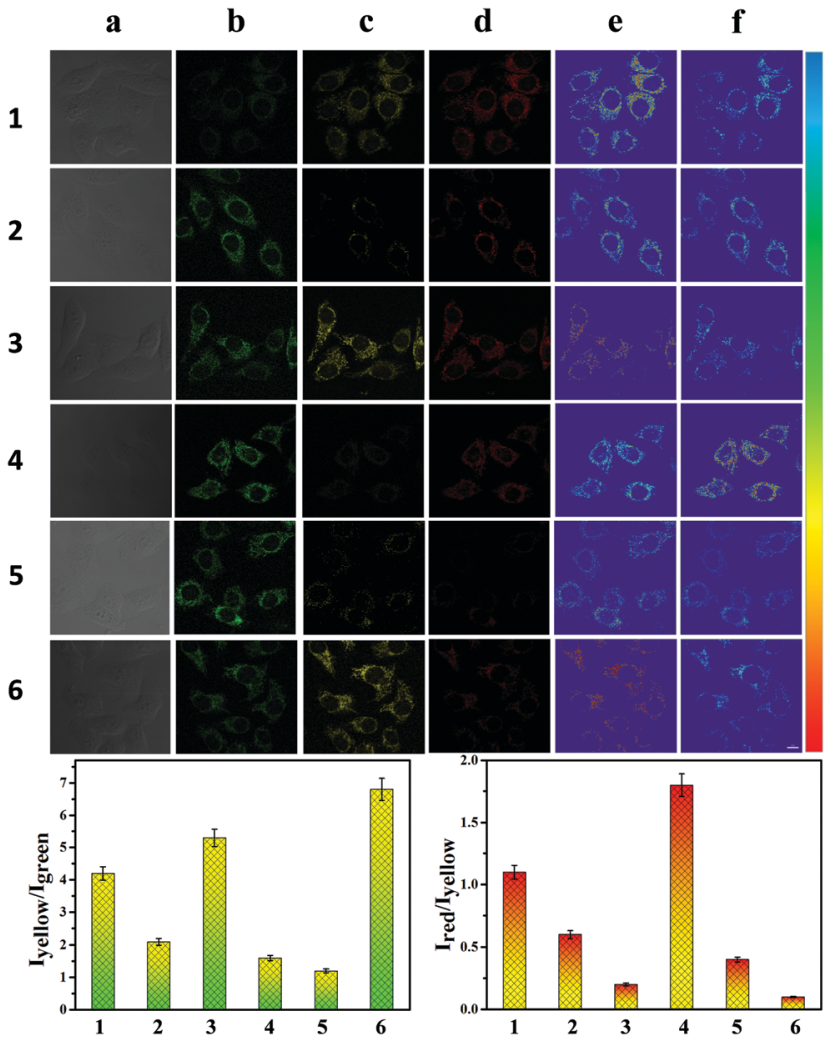

Fig. 4 Two-photon fluorescence images of HepG2 cells. (1) HepG2 cells incubated with CEMT $(10 \mu \mathrm{M})$ for 20 min. (2) HepG2 cells pre-treated with BNPP $(500 \mu \mathrm{M})$ before incubation with CEMT $(10 \mu \mathrm{M})$ for $20 \mathrm{~min}$. (3) HepG2 cells pre-treated with vinyl acetate $(500 \mu \mathrm{M})$ before incubation with CEMT $(10 \mu \mathrm{M})$ for $20 \mathrm{~min}$. (4). HepG2 cells pre-treated with BNPP $(500 \mu \mathrm{M})$ before the incubation with vinyl acetate $(500 \mu \mathrm{M})$ for $20 \mathrm{~min}$, followed by incubation with CEMT $(10 \mu \mathrm{M})$ for $20 \mathrm{~min}$. (5). HepG2 cells pre-treated with BNPP $(500 \mu \mathrm{M})$ before incubation with B-R buffer $(\mathrm{pH}=$ $4.98,40 \mathrm{mM})$ for $20 \mathrm{~min}$, followed by incubation with CEMT $(10 \mu \mathrm{M})$ for 20 min. (6). HepG2 cells pre-treated with benorilate $(500 \mu \mathrm{M})$ for $20 \mathrm{~min}$ before incubation with CEMT $(10 \mu \mathrm{M})$ for 20 min. Images were captured using $810 \mathrm{~nm}$ for two-photon excitation. Two-photon fluorescence emission window: (a) bright field. (b) Green channel (400-500 nm). (c) Yellow channel (500-570 nm). (d) Red channel (570-710 nm). (e) Ratio imaging: / /yellow//green. (f) Ratio imaging: / / red/lyellow. Scale bar: $20 \mu \mathrm{m}$.

$\mathrm{CE}$ activity and $\mathrm{pH}$. Compared with group 1, group 3 exhibited an enhanced green fluorescence intensity, indicating that CE participated in the metabolism of vinyl acetate and the activity of the CE decreased. However, the yellow fluorescence increased with decreasing red fluorescence, indicating that the metabolism of vinyl acetate resulted in a lowering of the $\mathrm{pH}$. Accordingly, the two ratios R1 $\left(I_{550} / I_{460}\right)$ and R2 $\left(I_{620} / I_{550}\right)$, displayed upward and downward trends respectively (Fig. 4-3). To verify the result, we pre-treated the cells with inhibitor BNNP before incubation with vinyl acetate. From Fig. 4-4, we can see that, compared with group 3 , this group displayed an enhanced fluorescence in the green channel and a weakened fluorescence in yellow channel, demonstrating the inhibition of CE. Finally, to verify that acidification was caused by the $\mathrm{CE}$ mediated metabolism of vinyl acetate, we used the B-R buffer to adjust the $\mathrm{pH}$ to 5.0 after the cells were pre-treated with BNNP. As shown in Fig. 4-5, compared with group 3, this group displayed a strong fluorescence in green channel, weak fluorescence in the yellow channel and negligible fluorescence in the red channel. Indicating, that $\mathrm{CE}$ facilitates acidification via mediation of the metabolism of vinyl acetate. Thus, we can use the signal of CEMT to detect acidification caused by CE-mediated hydrolysis of ester drugs. As an antipyretic drug, benorilate is widely used in the clinic. CE can metabolize benorilate to the acetylsalicylic acid resulting in a reduction of fever and inflammation. We then used the benorilate instead of vinyl acetate to perform the above imaging analysis. As Fig. 4-6 shows, compared with the control group 1, group 6 exhibited enhanced fluorescence in both the green and the yellow channel but weakened fluorescence in the red channel. Obviously, benorilate results in similar fluorescence changes to vinyl acetate, which indicates that benorilate participates in the CE-mediated metabolism and causes acidification. Moreover, the increased R1 $\left(I_{550} / I_{460}\right)$ and the decreased R2 $\left(I_{620} / I_{550}\right)$ further confirmed this result. Therefore, with its dual ratio signals, CEMT is able to reveal CE-mediated mitochondrial acidification. Considering the two-photon nature of CEMT, we then set out to test its applicability for tissue imaging. Since, the liver is responsible for drug metabolism, we used the probe to visualize the CE-mediated acidification during medication. Drug medication was performed with mice via the heart perfusion of vinyl acetate or benorilate (ESI $\dagger$ ). As shown in Fig. 5, compared with group 1, group 2 (vinyl acetate) and group 3 (benorilate) displayed increased fluorescence intensity in the green channel, indicating a decreased activity of CE due to its participation in drug metabolism.

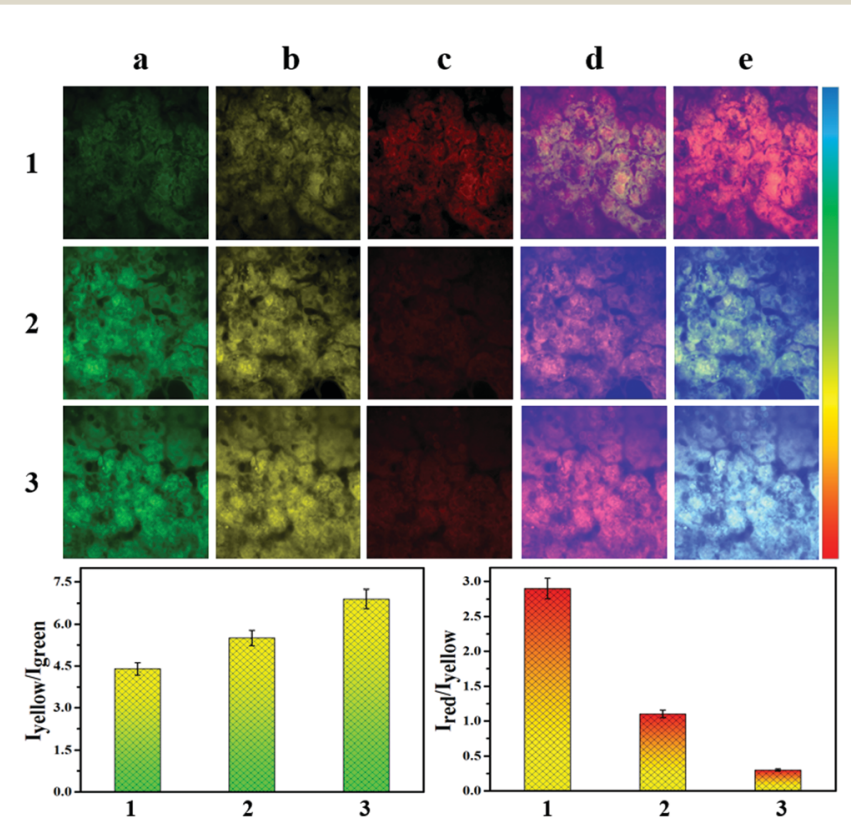

Fig. 5 Two-photon fluorescence images for liver of mice with cardiac perfusion: (1) CEMT $(20 \mu \mathrm{M})$ for $10 \mathrm{~min}$. (2) Pretreated with vinyl acetate $(1 \mathrm{mM})$ before with CEMT $(20 \mu \mathrm{M})$. (3) Pretreated with benorilate $(1 \mathrm{mM})$ before with CEMT $(20 \mu \mathrm{M})$ for $10 \mathrm{~min}$. Images were captured using $810 \mathrm{~nm}$ for two-photon excitation. Emission window: (a) green channel (400$500 \mathrm{~nm})$. (b) Yellow channel (500-570 nm). (c) Red channel (570-710 nm).

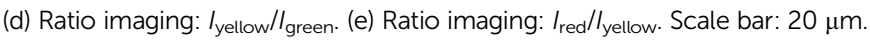


Moreover, the fluorescence ratios $I_{\text {yellow }} / I_{\text {green }}$ and $I_{\text {red }} /$ yellow exhibited upwards and downwards trends respectively. Thus, the two sets of data consistently demonstrated the CE mediated acidification during medication with ester drugs.

In summary, a dual ratiometric mitochondria-locked twophoton fluorescent molecular probe CEMT has been designed to detect $\mathrm{CE}$ activity and $\mathrm{pH}$. During medication with ester drugs, CEMT responded to CE-mediated acidification with an upward R1 $\left(I_{550} / I_{460}\right)$ and downward R2 $\left(I_{620} / I_{550}\right)$. Moreover, the mitochondrial targeting function allowed visualization of in situ information during acidification. The CEMT probe is an effective tool for the visualization of the CE-mediated acidification of cells and tissue, which is of great significance for the exploration of subcellular environmental changes mediated by enzymes.

This work was supported by National Natural Science Foundation of China (No. 21475074, and 21403123), the China Postdoctoral Science Foundation (2017M622254; 2016M600531), the Open Funds of the Shandong Province Key Laboratory of Detection Technology for Tumor Markers (KLDTTM2015-6; KLDTTM2015-9), and the Natural Science Foundation of Shandong Province (ZR201709240033). T. D. J. thanks the Royal Society for a Wolfson Research Merit Award.

\section{Conflicts of interest}

There are no conflicts to declare.

\section{Notes and references}

1 M. Gutova, G. M. Shackleford, V. Khankaldyyan, K. A. Herrmann, X. H. Shi, K. Mittelholtz, Y. Abramyants, M. S. Blanchard, S. U. Kim, A. J. Annala, J. Najbauer, T. W. Synold, M. D'Apuzzo, M. E. Barish, R. A. Moats and K. S. Aboody, Gene Ther., 2012, 20, 143.

2 (a) M. Hamasaki, N. Furuta, A. Matsuda, A. Nezu, A. Yamamoto, N. Fujita, H. Oomori, T. Noda, T. Haraguchi, Y. Hiraoka, A. Amano and T. Yoshimori, Nature, 2013, 495, 389; (b) R. Malli and W. F. Graier, Nat. Cell Biol., 2019, 21, 667-668.

3 T. Lieber, S. P. Jeedigunta, J. M. Palozzi, R. Lehmann and T. R. Hurd, Nature, 2019, 570, 380-384.

4 J. E. Lee, L. M. Westrate, H. Wu, C. Page and G. K. Voeltz, Nature, 2016, 540, 139.

5 (a) S. Erbas-Cakmak, S. Kolemen, A. C. Sedgwick, T. Gunnlaugsson, T. D. James, J. Yoon and E. U. Akkaya, Chem. Soc. Rev., 2018, 47,
2228-2248; (b) H.-W. Liu, L. Chen, C. Xu, Z. Li, H. Zhang, X.-B. Zhang and W. Tan, Chem. Soc. Rev., 2018, 47, 7140-7180; (c) J. Ning, W. Wang, G. Ge, P. Chu, F. Long, Y. Yang, Y. Peng, L. Feng, X. Ma and T. D. James, Angew. Chem., Int. Ed., 2019, 58, 9959; (d) W. Zhang, J. Zhang, P. Li, J. Liu, D. Su and B. Tang, Chem. Sci., 2019, 10, 879-883; (e) X. Wang, P. Li, Q. Ding, C. Wu, W. Zhang and B. Tang, J. Am. Chem. Soc., 2019, 141, 2061-2068; $(f)$ J. Ning, T. Liu, P. Dong, W. Wang, G. Ge, B. Wang, Z. Yu, L. Shi, X. Tian, X. Huo, L. Feng, C. Wang, C. Sun, J. Cui, T. D. James and X. Ma, J. Am. Chem. Soc., 2019, 141, 1126-1134; $(g)$ F. Ding, Z. Chen, W. Y. Kim, A. Sharma, C. Li, Q. Ouyang, H. Zhu, G. Yang, Y. Sun and J. S. Kim, Chem. Sci., 2019, 10, 7023-7028; (h) Z. Liu, X. Zhou, Y. Miao, Y. Hu, N. Kwon, X. Wu and J. Yoon, Angew. Chem., Int. Ed., 2017, 56, 5812-5816; (i) K. Dou, Q. Fu, G. Chen, F. Yu, Y. Liu, Z. Cao, G. Li, X. Zhao, L. Xia, L. Chen, H. Wang and J. You, Biomaterials, 2017, 133, 82-93.

6 (a) E. A. Halabi, Z. Thiel, N. Trapp, D. Pinotsi and P. Rivera-Fuentes, J. Am. Chem. Soc., 2017, 139, 13200-13207; (b) S. J. Park, H. W. Lee, H.-R. Kim, C. Kang and H. M. Kim, Chem. Sci., 2016, 7, 3703-3709; (c) Q. Jin, L. Feng, D.-D. Wang, Z.-R. Dai, P. Wang, L.-W. Zou, Z.-H. Liu, J.-Y. Wang, Y. Yu, G.-B. Ge, J.-N. Cui and L. Yang, ACS Appl. Mater. Interfaces, 2015, 7, 28474-28481; (d) Q. Jin, L. Feng, D.-D. Wang, J.-J. Wu, J. Hou, Z.-R. Dai, S.-G. Sun, J.-Y. Wang, G.-B. Ge, J.-N. Cui and L. Yang, Biosens. Bioelectron., 2016, 83, 193-199; (e) L. Feng, Z.-M. Liu, L. Xu, X. Lv, J. Ning, J. Hou, G.-B. Ge, J.-N. Cui and L. Yang, Chem. Commun., 2014, 50, 14519-14522; $(f)$ W. Chyan and R. T. Raines, ACS Chem. Biol., 2018, 13, 1810-1823; ( $g$ ) S. J. Park, Y. J. Kim, J. S. Kang, I. Y. Kim, K. S. Choi and H. M. Kim, Anal. Chem., 2018, 90, 9465-9471; (h) D.-D. Wang, Q. Jin, L.-W. Zou, J. Hou, X. Lv, W. Lei, H.-L. Cheng, G.-B. Ge and L. Yang, Chem. Commun., 2016, 52, 3183-3186; (i) J. Wang, Q. Chen, N. Tian, W. Zhu, H. Zou, X. Wang, X. Li, X. Fan, G. Jiang and B. Z. Tang, J. Mater. Chem. B, 2018, 6, 1595-1599.

7 (a) A. Wallabregue, D. Moreau, P. Sherin, P. Moneva Lorente, Z. Jarolímová, E. Bakker, E. Vauthey, J. Gruenberg and J. Lacour, J. Am. Chem. Soc., 2016, 138, 1752-1755; (b) D. Xu, Y. Li, C.-Y. Poon, H.-N. Chan, H.-W. Li and M. S. Wong, Anal. Chem., 2018, 90, 8800-8806; (c) M. H. Lee, N. Park, C. Yi, J. H. Han, J. H. Hong, K. P. Kim, D. H. Kang, J. L. Sessler, C. Kang and J. S. Kim, J. Am. Chem. Soc., 2014, 136, 14136-14142; (d) A. R. Sarkar, C. H. Heo, L. Xu, H. W. Lee, H. Y. Si, J. W. Byun and H. M. Kim, Chem. Sci., 2016, 7, 766-773; (e) X. Liu, Y. Su, H. Tian, L. Yang, H. Zhang, X. Song and J. W. Foley, Anal. Chem., 2017, 89, 7038-7045; $(f)$ M.-Y. Wu, K. Li, Y.-H. Liu, K.-K. Yu, Y.-M. Xie, X.-D. Zhou and X.-Q. Yu, Biomaterials, 2015, 53, 669-678; $(g)$ L. Wang, X. Zhu, C. Xie, N. Ding, X. Weng, W. Lu, X. Wei and C. Li, Chem. Commun., 2012, 48, 11677-11679; (h) G. Chen, Q. Fu, F. Yu, R. Ren, Y. Liu, Z. Cao, G. Li, X. Zhao, L. Chen, H. Wang and J. You, Anal. Chem., 2017, 89, 8509-8516; $(i)$ A.-M. Luo, Y. Shao, K.-J. Zhang, Y.-W. Wang and Y. Peng, Chin. Chem. Lett., 2017, 28, 2009-2013; (j) X. Sun, Y.-W. Wang and Y. Peng, Org. Lett., 2012, 14, 3420-3423.

8 J. R. Kuykendall, M. L. Taylor and M. S. Bogdanffy, Toxicol. Appl. Pharmacol., 1993, 123, 283-292. 